\title{
Síndrome de Lemiere por SAMS. Reporte de caso pediátrico
}

\author{
Methicillin-sensitive Staphylococcus Aureus (MSSA)- \\ associated Lemierre's Syndrome. A Pediatric case report
}

\author{
Gloria Celeste Samudio Domínguez ${ }^{(1)}$, Elizabeth Irala ${ }^{(1)}$, Jorge Ruiz-Díaz ${ }^{(1)}$
}

\section{RESUMEN}

El síndrome de Lemierre es una infección severa que se caracteriza por trombosis de vena yugular como consecuencia de la infección de parte profunda de cuello. Conocida también como sepsis por angina, es potencialmente letal. El alto índice de sospecha, aunado a los métodos diagnósticos por imágenes, permite el diagnóstico en forma temprana y oportuna, hecho que incide en la evolución favorable. Se presenta aquí el caso de un paciente pediátrico con diagnóstico de Síndrome de Lemierre por SAMS, tratado en forma exitosa.

Palabras clave: Síndrome de Lemierre, pediatría, Staphylococcus aureus meticilino sensible.

\section{INTRODUCCIÓN}

Las infecciones de cabeza y cuello que ponen en peligro la vida de quien las padece son relativamente poco frecuentes en la era posantibiótica. Descrita por Lemierre, en 1936, como la sepsis posanginal ${ }^{(1)}$, pasó de ser una infección frecuente y de características clínicas fácilmente reconocibles, a una entidad rara en nuestros tiempos. Actualmente el síndrome de Lemierre es considerada una "enfermedad olvidada" y se piensa raramente en ella ${ }^{(2)}$.

Es una infección potencialmente letal, inicialmente causada por Fusobacterium necrophorum, sin embargo la etiología es diferente en nuestros días,

\begin{abstract}
Lemierre's Syndrome is a severe infection characterized by jugular vein thrombosis resulting from infection of deep portion of the neck. Also known as post-anginal sepsis, the condition is potentially lethal. A high index of suspicion, coupled with diagnostic imaging methods, allows for early diagnosis and timely treatment, which can lead to a favorable outcome. We report the case of a pediatric patient diagnosed with MSSA Lemierre syndrome associated with MSSA, which was successfully treated.
\end{abstract}

Keywords: Lemierre's Syndrome, pediatrics, methicillinsensitive Staphylococcus aureus.

pudiendo ser causada por diversas bacterias ${ }^{(3)}$.

Un alto índice de sospecha debe tenerse en cuenta para realizar diagnóstico y abordajes oportunos. El objetivo del presente trabajo es reportar el caso de un paciente pediátrico con diagnóstico de Síndrome de Lemierre por SAMS, tratado en forma exitosa.

\section{CASO CLÍNICO}

Paciente de 12 años, de sexo masculino que acude a la consulta con historia de dolor cervical de 4 días de evolución, acompañado de tumoración en región

\footnotetext{
1. Departamento de Pediatría. Servicio de Cirugía Vascular. Hospital Nacional Itauguá Guazú. Paraguay.

Correspondencia: Gloria Celeste Samudio Domínguez. E-mail: gsamudio.samudio@gmail.com

Recibido: 21/09/2015; Aceptado: 20/11/2015

Los autores declaran que no existen conflictos de interés en el presente estudio.

http://dx.doi.org/10.18004/ped.2015.diciembre.225-228
} 
cervical izquierda que aumenta de tamaño con los días, con dificultad para movilizar el cuello. Fiebre de 4 días de evolución, elevada, no graduada, contínua. Vómitos en varias oportunidades, de contenido de restos alimentarios y Deposiciones líquidas sin sangre ni gleras en número 4 a 5 en 24 horas. Estos dos últimos síntomas de 48 horas de evolución. Confusión 4 horas antes del ingreso, con pérdida de control de esfínteres. No refieren convulsiones tónico clónicas.

Ingresa caminando, acompañado de familiares, luce en buen estado general, llama la atención tumoración en cuello que ocupa todo el lado izquierdo y región de la nuca, Glasgow 15/15, Signos vitales al ingreso: FC: 120x' ; FR: 20x'; to $36,6{ }^{\circ} \mathrm{C}$. Índices antropométricos: Peso: $34 \mathrm{~kg}$.( percentil 75); Talla: 1,55 metros (percentil 90); Perímetro cefálico: $54 \mathrm{~cm}$. (percentil 50).

Al examen físico: la tumoración abarca toda la región lateral izquierda y de la nuca, de límites mal definidos, muy dolorosa, no eritematosa, sin latido, duro elástico, superficie lisa, dificulta la movilidad del cuello. En pulmones se ausculta murmullo vesicular rudo bilateral. Se palpa hígado a $2 \mathrm{~cm}$ del reborde costal.

Se realiza hemograma donde presenta número de blancos 9300, con predominio de neutrófilos $(72 \%)$, plaquetas normales, PCR 32 (para valor normal 0,6), hiponatremia leve, urea y perfil hepático ligeramente aumentados.

Radiografía de tórax con infiltrado intersticial bilateral, con predominio derecho. Tomografía de cráneo normal, en cuello varias formaciones nodulares.

Ingresa con los diagnósticos de tumoración en región cervical de etiología a determinar y neumonía bilateral a predominio derecho. Se toman muestras para hemocultivos e inicia cobertura con Cefotaxima (300), Vancomicina (60), Hidratación parenteral, Difenilhidantoína carga y mantenimiento, Salbutamol en aerosol.

Luego de 8 horas del ingreso, presenta sudoración profusa, sialorrea, aleteo nasal, el Glasgow se vuelve alternante, por lo que ingresa a Cuidados Intensivos, donde se agrega oxígeno en cánula nasal a las indicaciones citadas más arriba.
Luego de 48 horas se constata abundante secreción purulenta en boca, que se cultiva. Presenta cianosis generalizada con bradicardia por lo que se intuba al paciente y se ventila en forma asistida con parámetros bajos. Se constata, además, salida de pus por el oído izquierdo. Continuó febril, el hemograma empeoró, presentando leucocitosis de 15.900 con neutrófilos $90 \%$, granulaciones tóxicas $10 \%$. Se agregó metronidazol. Se inició Dexametasona por el estridor laríngeo que presentaba antes de su intubación, y Manitol sospechando edema cerebral y se mantuvo por 3 días. Sedación con Fentanilo y Midazolán en goteo contínuo y Dopamina con Noradrenalina por 2 días.

El resultado de Hemocultivos positivo a Staphylococcus aureus meticilino sensible (SAMS).

Se realiza ecografía de partes blandas de cuello donde se visualiza imagen hipoecogénica a lo largo de toda la luz de la Vena Yugular compatible con un trombo, y en TAC de cuello presenta absceso retrofaríngeo de grandes dimensiones y trombosis de vena yugular interna (Figura 1 y 2). Con este diagnóstico, inició Heparina de bajo peso molecular por 10 días.

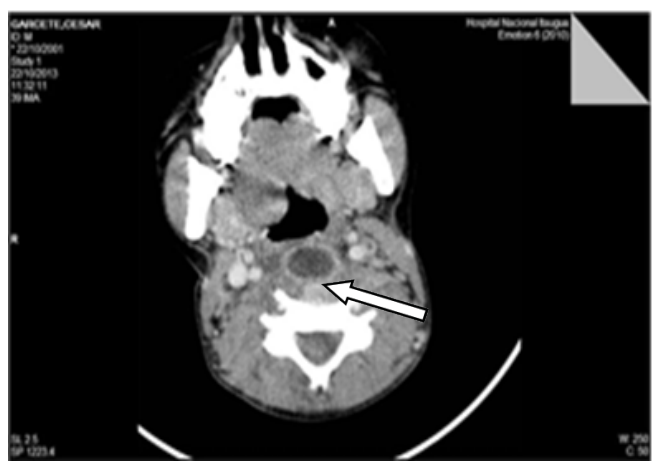

Figura 1. Absceso retrofaríngeo importante (flecha blanca). Obsérvese la asimetría en los vasos del paquete vasculonervioso del cuello.

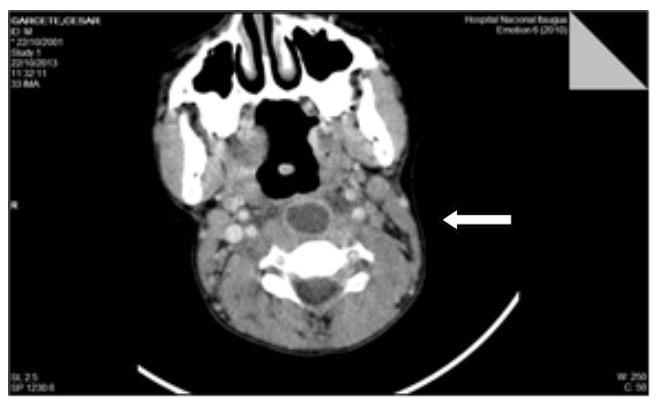

Figura 2. Trombosis de vena yugular interna (flecha blanca) Se puede observar la pared de la vena, pero sin contenido (centro negro). Se observa además el absceso. 
Al 14to. día de internación, ya extubado, se traslada a sala de menor complejidad, completa 14 días de Vancomicina y 7 días de Amikacina, el paciente seguía febril. Se decidió disminuir el espectro para adecuar a sensibilidad del SAMS. Se rota a Oxacilina y la fiebre desaparece al día 5 to del inicio de la misma.

Se realizaron estudios para descartar trastornos en la coagulación, Fibrinógeno, Factor VIII, Factor IX, Proteína C y S, Antitrombina III, Ácido fólico, Troponina, que retornan todos normales. Recibió Acenocumarol por 7 días. Fue dado de alta en buenas condiciones, sin secuelas neurológicas.

En la consulta ambulatoria al tercer y sexto meses de externado, el niño se encontraba en buen estado general, con persistencia aún de la trombosis, pero con formación de vasos colaterales, según informe de eco dopler.

\section{DISCUSIÓN}

El síndrome de tromboflebitis séptica de la vena yugular interna, asociada a infección orofaríngea, bacteriemia y metástasis de la infección a focos distantes, principalmente embolias sépticas pulmonares, es reconocido con el nombre de Síndrome de Lemierre ${ }^{(3)}$.

Esta afección está causada principalmente por el anaerobio Fusobacterium necrophorum ${ }^{(4-6)}$. Aunque otros gérmenes tales como Enterococcus faecalis puede presentarse ${ }^{(7)}$. Se han reportado casos secundarios a otro tipo de infecciones de cabeza y cuello como mastoiditis, otitis media aguda y celulitis ${ }^{(8-10)}$.

Este cuadro es más frecuente en adultos jóvenes previamente sanos, sin déficit inmunitario, hábitos tóxicos ni otros factores de riesgo predisponentes ${ }^{(11-12)}$.

La bacteremia por Staphylococcus aureus meticilino resistente adquirido en la comunidad (SAMR-CA) puede ocasionar secuelas pulmonares. Cuando se asocia a faringitis, o linfadenitis parafaríngea, el paciente puede llegar a padecer de Síndrome de Lemierre. Muchas veces la faringitis puede estar ausente, ya que el estado de portación del SAMR-CA puede ser asintomático, encontrándose en las narinas, por lo tanto es importante tener en cuenta este germen aún en casos donde aparentemente no existen factores que indiquen una posible infección estafilocócica $^{(13-16)}$.

Cuanto más tempranos el diagnóstico y tratamiento oportunos, el pronóstico de paciente será mejor. La terapia endovenosa debe cubrir gérmenes anaerobios, y en nuestro hospital, por la alta prevalencia de SAMR-CA ${ }^{(17)}$, recomendamos la cobertura de dicho germen con vancomicina, hasta obtención de cultivos. En nuestro paciente se cubrió tanto anaerobios como SAMR, disminuyendo el espectro cuando se recibieron los cultivos y sensibilidad del germen implicado.

El tratamiento debe durar 3 a 6 semanas. El drenaje quirúrgico es altamente recomendado, ya que favorece la recuperación temprana y permite la identificación del agente causal, lo que facilita la elección más asertiva del antibiótico. En el caso que nos ocupa, no se realizó el drenaje quirúrgico de la lesión, drenando la misma en forma espontánea en etapas tempranas de la internación.

La anticoagulación en esta patología aún permanece en controversia. Si no existe contraindicación, la terapia anticoagulante debe considerarse en paciente de alto riesgo. Nuestro paciente recibió anticoagulación endovenosa al principio y luego vía oral, completando sólo 17 días, luego de lo cual se retiró, sin presentar ningún tipo de complicación ${ }^{(18)}$.

El Síndrome de Lemierre es una patología infecciosa grave y potencialmente fatal que requiere de un diagnóstico y tratamiento oportuno para mejorar la sobrevida de los pacientes. En nuestro medio, se debería cubrir empíricamente el SAMR-CA debido a su alta prevalencia.

\section{REFERENCIAS}

1. Lemierre A. On certain septicemias due to anaerobic organisms. Lancet. 1936;1:701-3.

2. Moffett KS. Pediatric infectious disease: unusual head and neck infections. Oral Maxillofac Surg Clin North Am. 2012;24(3):469-86. doi: 10.1016/j.coms.2012.05.008. Epub 2012 Jun 26. 
3. Laupland, Kevin B. Vascular and parameningeal infections of the head and neck. Infectious Disease Clinics. 2012;21(2):577-590.

4. Karkos PD, Asrani S, Karkos C, Leong S, Theoc hari E, Alexopo ulou T, Assimakopo ulos A. Lemierre's syndrome: a systematic review. Laryngoscope. 2009;119:1552-59.

5. Rior dan T. Human infection with Fusobacterium necrophorum (necrobacillosis), with a focus on Lemierre's syndrome. Clin Microbiol Rev. 2007;20:622-59.

6. Brook, I. Microbiology and management of deep facial infections and Lemierre syndrome. ORL J Otorhinolaryngol Relat Spec. 2003;65:117-120.

7. Winter DM, Saavedra-BA, Grau-LC, Caro-L. Lemierre syndrome: a case report. J Rev Otorrinolaringol Cir Cabeza Cuello. 2013;73:164-68.

8. Chirinos JA, Garcia J, Alcaide ML, Toledo G, Baracco GJ, Lichtstein DM. Septic thrombophlebitis: diagnosis and management. Am J Cardiovasc Drugs. 2006;6:9-14.

9. Andrade JT, San Martín JT, Grau C. Síndrome de Lemierre, secundario a otitis media aguda: revisión a partir de un caso. Rev Otorrinolaringol Cir Cabeza Cuello [revista en Internet]. 2013; Dic [citado 2015 Jun 06]; 73(3):263-67. Disponible en: http://www.scielo.cl/scielo.php?script=sci_ arttext\&pid=S0718-48162013000300009\&lng=es

10. Juárez I, Díaz-C A, Aboul-Hons S, Monner-D A, Marí$\mathrm{R} A$. Síndrome de Lemierre asociado a infecciones odontógenas caso clínico y revisión de la literatura. Med Oral, Patología Oral y Cirugía Bucal, 2007;12(5):326-28.

11. De Sena S, Rosenfeld DL, Santos S, Keller I. Jugular thrombophlebitis complicating bacterial pharyngitis (Lemièrre`s syndrome). Pediatr Radiol. 1996;141-4.

12. Karanas YL, Yim KK, Shuster BA, Lineaweaver WC. Lemièrre`s syndrome: a case of postanginal septicemia and bilateral flank abscesses. Ann PlatSurg. 1995;35:525-28

13.Kizhner V, Samara G, Panesar R, Krespi YP. Methicillinresistant Staphylococcus aureus bacteraemia associated with Lemierre's syndrome: case report and literature review. J Laryngol Otol. 2013;127(7):721-23. doi: 10.1017/S0022215113001035. Epub 2013 May 24.

14. Molloy A, Towersey G, Shackleton D, Aali A, Ash S. The changing face of an old disease: case report of nonclassical Lemierre's syndrome caused by a Panton-Valentine leucocidin-positive methicillin-susceptible Staphylococcus aureus isolate. J Clin Microbiol. 2012;50(9):3144-45. doi: 10.1128/JCM.00939-12. Epub 2012 Jul3.

15. Pitsiou G, Kachrimanidou M, Papa A, Kioumis I, Paspala A, Boutou A, Vlachou S, Tsorlini E, Argyropoulou-Pataka P. Lemierre's syndrome presenting to the ED: rapidly fatal sepsis caused by methicillinsusceptible Staphylococcus aureus, Staphylococcus protein A type t044. Am J Emerg Med. 2013;31(1):268. doi: 10.1016/j.ajem.2012.04.028. Epub 2012 Jul 15.

16. Chanin JM, Marcos LA, Thompson BM, Yusen RD, Dunne WM Jr, Warren DK, Santos CA. Methicillinresistant Staphylococcus aureus USA300 clone as a cause of Lemierre's syndrome. J Clin Microbiol. 2011;49(5):206366. doi: 10.1128/JCM.02507-10. Epub 2011 Mar 23.

17. Samudio-Domínguez GC, Bordón L, D`apollo N, Martínez Bareiro M, Benítez D. Patrones de sensibilidad de Staphylococcus aureus de la comunidad aislados de niños con infecciones de piel y partes blandas. Pediatr (Asunción) [revista en Internet]. 2015; Apr [citado 2015 Sep 21] 42(1):31-36. Disponible en: http://scielo.iics.una.py/scielo. php? script $=$ sci_arttext $\&$ pid $=$ S1683-980320150001000 $05 \& \operatorname{lng}=\mathrm{en}$

18. Phan T, So TY. Use of anticoagulation therapy for jugular vein thrombus in pediatric patients with Lemierre's syndrome. Int J Clin Pharm. 2012;34(6):818-21. doi: 10.1007/s11096-012-9684-5. Epub 2012 Aug 17. 